\title{
KEMAMPUAN PEGAWAI BUMDES DALAM MENGAPLIKASIKAN ZAHIR DALAM PEMBUATAN LAPORAN KEUANGAN DI DESA PEMATANG SERAI TANJUNG PURA DI SUMATERA UTARA
}

\author{
Vina Arnita ${ }^{1}$, Hernawaty $^{1}$, Eky Ermal $\mathbf{M}^{2}$ \\ 1Fakultas Sosial Sains Universitas Pembangunan Panca Budi \\ 2Fakultas Ekonomi dan Bisnis Universitas Medan Area \\ vinaarnita@dosen.pancabudi.ac.id
}

\begin{abstract}
In this dedication, the researcher helps provide solutions to Bumdes employees to make financial reports. At the beginning of this dedication, the researchers visited Pematang Village, Lemongrass, Tanjung Pura, and Bumdes employees told of their strengths and weaknesses. The deficiencies faced by them were also explained during the visit. The village residents who were in the area of Lemongrass Temple were one of the villages that received grants from the central government. So the problems that arise they do not understand to make computerized financial statements. With this problem, the researchers took part in alleviating their problems in making financial statements. The disadvantage they faced was that the employees in Bumdes only graduated from high school, so they did not know how to make an accurate financial report. The educational background for Bumdes employees makes it difficult for them to understand financial statements; researchers provide learning about accounting and accounts from accounting. After they know, new accounts are entered into journals. By completing accounts and journals, then they can enter financial reports through the zahir application.
\end{abstract}

Keywords: Accounting, zahir, report statement

\begin{abstract}
Abstrak
Dalam pengabdian ini peneliti membantu memberikan solusi kepada karyawan Bumdes untuk membuat laporan keuangan. Pada awal pengabdian ini, peneliti mengunjungi Desa Pematang, Sereh, Tanjung Pura, dan karyawan Bumdes menceritakan kelebihan dan kekurangannya. Kekurangan yang mereka hadapi juga dijelaskan selama kunjungan. Warga desa yang berada di kawasan Candi Serai merupakan salah satu desa penerima hibah dari pemerintah pusat. Sehingga permasalahan yang muncul mereka kurang paham untuk membuat laporan keuangan yang terkomputerisasi. Dengan masalah tersebut peneliti turut serta meringankan permasalahan mereka dalam membuat laporan keuangan. Kerugian yang mereka hadapi adalah para pegawai di Bumdes hanya lulusan SMA, sehingga tidak tahu bagaimana membuat laporan keuangan yang benar. Latar belakang pendidikan karyawan Bumdes membuat mereka kesulitan untuk memahami laporan keuangan, peneliti memberikan pembelajaran tentang akuntansi dan akun dari akuntansi. Setelah mereka memahami akun baru dimasukkan ke dalam jurnal. Dengan melengkapi akun dan jurnal, maka mereka dapat memasukkan laporan keuangan melalui aplikasi zahir.
\end{abstract}

Kata kunci: Akuntansi, zahir, Laporan Pernyataan

MARTABE : Jurnal Pengabdian Masyarakat|118 
Vina Arnita, dkk. Kemampuan Pegawai Bumdes Dalam Mengaplikasikan Zahir ...

\section{PENDAHULUAN}

Perkembangan teknologi tidak hanya terpaut pada barang-barang elektronik tetapi juga ia memengaruhi mekanisme pencatatan dalam wawasan akuntansi. Modernisasi akuntansi memberi perubahan yang amat signifikan terhadap sistem itu sendiri. Akibatnya efisiensi waktu dielu-elukan amat menyokong staf dan pengusaha dalam mengambil keputusan bisnis. Dampaknya kinerja perusahaan dapat diketahui oleh pelbagai pihak sedini mungkin termasuk publik yang memang tengah ingin berinvestasi pada perusahaan terbuka.

Sisi positif dalam sistem akuntansi kontemporer setidaknya menciptakan terobosan baru dengan maksud mengajak para staf akuntansi dan akuntan agar lebih memercayai sistem terpadu yang dirancang sedemikian rupa keakuratannya. Ini juga sekaligus melenyapkan anggapan bahwa pencatatan manual bahkan yang sudah terlampau konvensional dengan cara menulis di atas buku sudah sangat ketinggalan zaman.

Adapun tahapan yang terbukti sederhana dan mudah diterapkan untuk membuat laporan keuangan adalah sebagai berikut :

\section{Pembuatan data kerja baru}

Tahapan ini memandu pengguna untuk mengisi identitas perusahaan, periode awal akuntansi, pemilihan bidang usaha, pembuatan COA standar otomatis, dan pemilihan mata uang.

\section{Pengisian data master}

Pengguna dengan mudah mengisi data nama dan alamat, penyesuaian COA, data barang, dll.

\section{Pengisian saldo awal}

Perusahaan yang sudah berdiri sebelum menggunakan sistem akuntansi terpadu dapat mengisi saldo awal akun, piutang usaha, utang usaha, dan persediaan barang.

\section{Memasukkan transaksi}

Awali dengan memilah notanota transaksi ke dalam kategori transaksi misalnya pembayaran iuran masuk sebagai transaksi jurnal umum, penjualan masuk sebagai transaksi jurnal khusus, dsb.Di dalam sistem akuntansi terpadu, pencatatan jurnal umum disediakan dalam modul khusus misalnya modul Buku Besar. Pengguna cukup mengeklik modul tersebut dan tampillah fasilitas penginputan jurnal umum. Pilih akun yang sesuai di sisi debit dan kredit, masukkan nilainya, lalu rekam/ simpan. Semua transaksi sudah otomatis diposting ke buku besar setelah pengguna mengeklik tombol posting.

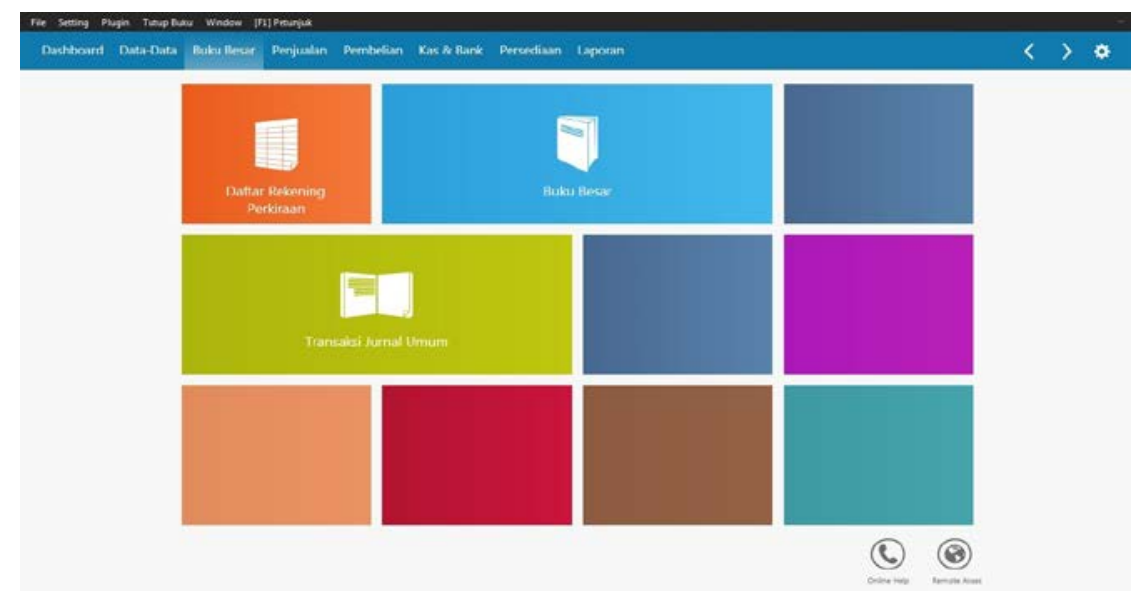

Gambar 1. Pembuatan Data Kerja Baru 

Vina Arnita, dkk. Kemampuan Pegawai Bumdes Dalam Mengaplikasikan Zahir ...

Pencatatan pembelian/ penjualan disediakan juga dalam modul khusus dengan fasilitas yang disajikan lengkap meliputi pengadaan barang, penawaran harga, pemesanan barang/jasa, pesan hantar, invoicing, retur, pembayaran utang/piutang, dll.

Jika pengguna akan menyesuaikan persediaan barang atau mungkin melakukan stock opname, sistem pun menyediakan modul Persediaan yang di dalamnya terdapat fasilitas pemakaian/ penyesuaian barang, perakitan, pembongkaran, pemindahan barang antargudang, transaksi konsinyasi, dll.

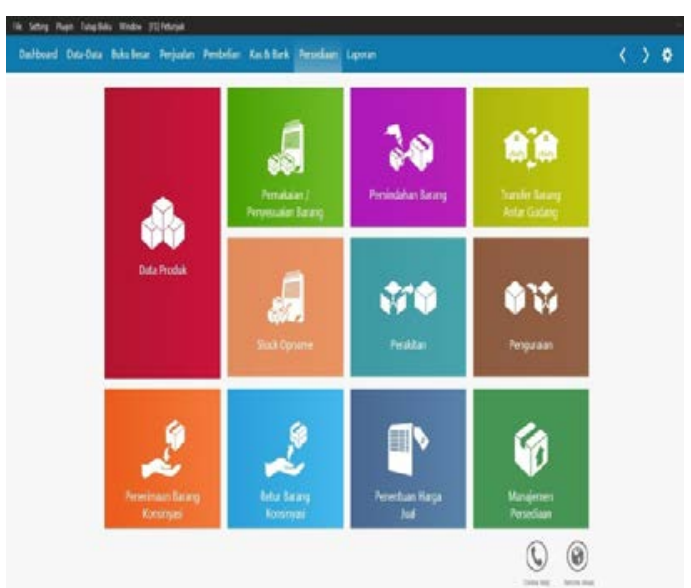

Gambar 2. Memasukkan Transaksi

\section{Pencatatan transaksi transfer tunai, pembelian harta tetap, penerimaan modal, pembayaran dengan giro, dll dapat dicatat di modul Kas \& Bank.}

\section{Pemeriksaan ulang}

Periksa kebenaran data yang telah diinput dari fasilitas alat bantu, misalnya dengan menghitung ulang saldo akhir akun, hitung ulang saldo akhir persediaan barang, cek jurnal yang tidak balance, dsb.

\section{Tutup Buku Akhir}

Suatu software akuntansi dilengkapi juga dengan fasilitas tutup buku akhir bulan dan tahun. Ini memungkinkan pengguna tidak perlu lagi menjurnal manual tutup buku, penyusutan, dsb.

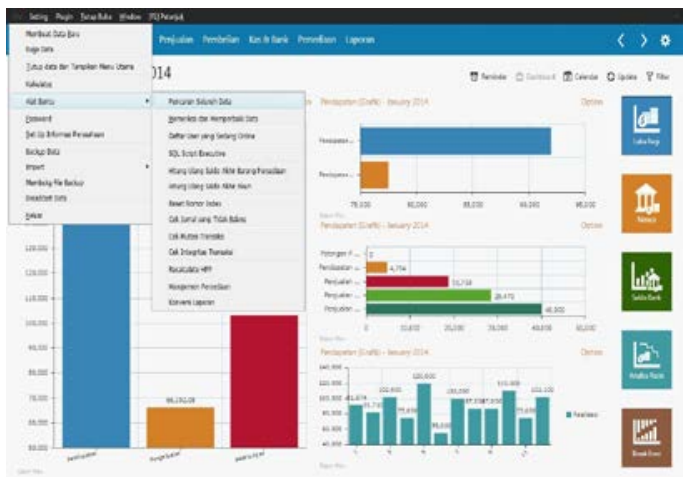

Gambar 3. Pemeriksaan Ulang

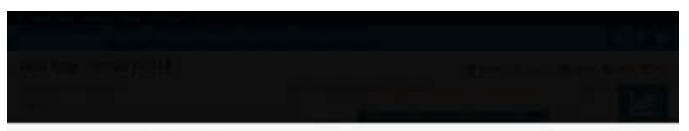

Fesilitas otomests
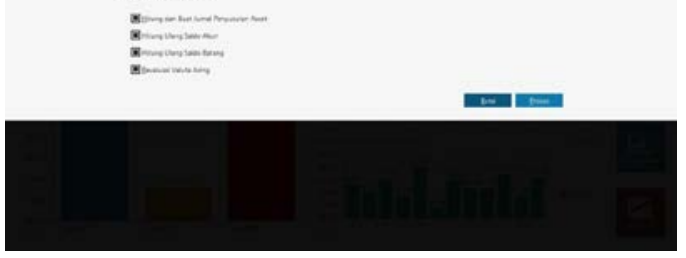

Gambar 4. Tutup Buku Akhir

\section{Laporan Keuangan Terbentuk Otomatis}

Cukup mengeklik tombol posting di setiap transaksi atau secara massal, transaksi masuk ke buku besar secara otomatis. Dengan demikian, buku besar pembantu, laporan keuangan, dan laporan pembantu pun terbentuk secara otomatis pula.

\section{METODE}

Masyarakat merupakan khalayak yang dianggap perlu dan penting untuk mengetahui permasalahan tentang pembuatan laporan keuangan.Karena mereka dituntut untuk mengetahui bagaimana cara pembuatan laporan keuangan secara komputerisasi.Permasalahan yang muncul adalah pegawai yang terbentuk diBUMDES itu bukan memiliki latarbelakang pendidikan akuntansi. 
Oleh karena itu mereka sangat sulit memahami akun-akun akuntansi yang akan dimasukan kedalam jurnal. Tim pengajar diharapkan bisa ikut mensosialisasikan tentang pelaporan laporan keuangan dengan menggunakan aplikasi zahir. Masalah utama yang ditemukan adalah pegawai BUMDES masih kurang pemahaman aakun-akun ataupun transaksi yang telah terjadi. Adanya kondisi tersebut sehingga perlu dilakukan sosialisasi dan penyuluhan kepada pegawai BUMDES, agar mereka dapat menguasai sistem pelaporan keuangan dengan menggunakan aplikasi sehingga akan memudahkan mereka dalam membuat pelaporan keuangan.

\section{HASIL DAN PEMBAHASAN}

Sesuai dengan judul Pengabdian ini yaitu "Pengetahuan Akuntansi Komputer Berbasis Zahir Di Desa Pematang Serai Tanjung Pura” dengan metode praktek dan memberikan aplikasi dalam bentuk software untuk digunakan dalam pembuatana laporan keuangan serta tanya jawab, dan membagikan modul kepada peserta sebagai alat bantu dalam pembekalan.

Luaran yang diharapkan dari Pengabdian Masyarakat ini adalah : Diharapkan mampu menambah pemahaman dalam membuat laporan keuangan dan pegawai Bumdes dapat menyajikan laporan keuangan sesuai standar akuntansi. Adapun capaian target dari pengabdian masyarakat adalah:

1. Pegawai Bumdes memperoleh pengetahuan dan secara langsung berupa penginputan akun-akun transaksi kedalam jurnal dan pembuatan laporan keuangan

2. Memberikan sosialisasi dan pemahaman tentang postingan akunakun kedalam jurnal.

3. Memberikan pelatihan secara praktikal dengan membuat laporan keuangan yaitu laporan laba rugi,perubahan modal dan laporan neraca saldo.

\section{UCAPAN TERIMA KASIH}

Ucapan terimakasih saya sampaikan kepada Bumdes Pematang Serai Tanjung pura dan Universitas Pembangunan Panca Budi Medan.

\section{DAFTAR PUSTAKA}

Ayub, $\quad 2009$. Understanding Islamic Finance. Jakarta: Gramedia Pustaka Utama

Departemen Agama RI. 2009. AlQur'an dan Terjemahanya, Bandung : PT. Sygma Examedia Arkanleema

Djakman D Chaerul. 1999. Dasar-dasar Manajemen Keuangan. Jakarta : Salemba Empat

Manulang, M. 1990. Dasar-dasar Manajemen. Jakarta: Ghalia Indonesia

Muhammad. 2011. Manajemen Bank Syariah. Yogyakarta: UPP STIM YKPN

Soemitra, Andri. 2010. Bank \& Lembaga Keuangan Syariah. Jakarta: Kencana

Yusanto, M. I. dan M.K. Widjajakusuma. 2002. Menggagas Bisnis Islami, Jakarta: Gema Insani Press 